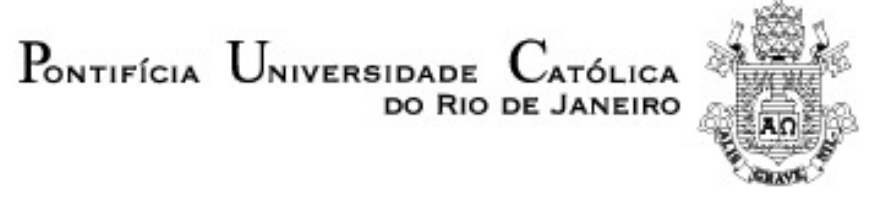

Silvia Regina da Silva Barros da Cunha

\title{
As marionetes divinas: \\ o fundamento da responsabilidade moral no pensamento de Platão
}

\begin{abstract}
Dissertação de Mestrado
Dissertação de mestrado apresentada como requisito parcial para obtenção do grau de Mestre pelo Programa de Pós-graduação em Filosofia da PUC-Rio
\end{abstract}

Orientador: Prof ${ }^{\underline{a}}$ Maura Iglésias

Rio de Janeiro Março de 2011 
Pontifícia Universidade Do Rio de Janeiro $_{\text {dica }}$

\section{Silvia Regina da Silva Barros da Cunha}

\section{As marionetes divinas: o fundamento da responsabilidade moral no pensamento de Platão}

Dissertação apresentada como requisito parcial para obtenção do grau de Mestre pelo Programa de Pós-graduação em Filosofia do Departamento de Filosofia do Centro de Teologia e Ciências Humanas da PUC-Rio. Aprovada pela Comissão Examinadora abaixo assinada.

\section{Prof ${ }^{a}$ Maura Iglésias}

Orientadora

Departamento de Filosofia - PUC-Rio

Prof. Fernando Augusto da Rocha Rodrigues

Departamento de Filosofia - UFRJ

Prof. Fernando Décio Porto Muniz

Departamento de Filosofia - UFF

Prof ${ }^{a}$ Denise Berruezo Portinari

Coordenador Setorial do Centro de Teologia e

Ciências Humanas - PUC-Rio

Rio de Janeiro, 14 de março de 2011. 
Todos os direitos reservados. É proibida a reprodução total ou parcial do trabalho sem autorização da universidade, do autor e do orientador.

\section{Silvia Regina da Silva Barros da Cunha}

Graduou-se em Direito pela Universidade do Estado do Rio de Janeiro - UERJ em 1983. Concluiu especialização em Filosofia Geral pela Faculdade de São Bento do Rio de Janeiro (FSBRJ) em 2009. Foi advogada do Banco Nacional de Desenvolvimento Econômico e Social - BNDES de 1984 a 1994, admitida mediante aprovação em concurso público. Atualmente é Juíza do Trabalho, Titular da $39^{a}$ Vara de Conciliação de Julgamento do Rio de Janeiro. $\mathrm{Na}$ área acadêmica, é membro do Núcleo de Estudos em Filosofia Antiga - NUFA, da Pontifícia Universidade Católica do Rio de Janeiro.

Ficha Catalográfica

Cunha, Silvia Regina da Silva Barros da

As marionetes divinas : o fundamento da responsabilidade moral no pensamento de Platão / Silvia Regina da Silva Barros da Cunha ; orientadora: Maura Iglesias. - 2010.

$91 \mathrm{f} . ; 30 \mathrm{~cm}$

Dissertação (mestrado)-Pontifícia Universidade Católica do Rio de Janeiro, Departamento de Filosofia, 2010. Inclui bibliografia

1. Filosofia - Teses. 2. Leis. 3. Responsabilidade moral. 4. Fontes do mal em Platão. I. Iglesias, Maura. II. Pontifícia Universidade Católica do Rio de Janeiro. Departamento de Filosofia. III. Título. 
Aos meus filhos, André e Júlia 


\section{Agradecimentos}

À minha orientadora, Professora Maura Iglésias, figura humana ímpar, tanto por seu notável saber como por sua firmeza moral.

Aos Professores Fernando Décio Porto Muniz, Fernando Augusto da Rocha Rodrigues e Irley Franco, pela honrosa participação em minha banca.

À Prof ${ }^{a}$ Maria Inês Senra Anachoreta, amiga em momentos difíceis.

Ao Prof. Guilherme Domingues da Motta, amigo querido, pela leitura atenta e paciente de meu trabalho e pelas sugestões.

Aos colegas Kátia Frecheiras e Rafael Huguenin, sempre solidários.

Aos meus filhos, André e Júlia, que em muito colaboraram para o resultado do trabalho, com obtenção de artigos, revisão das traduções para o Inglês e que pacientemente me ensinam a usar o computador.

À amiga Solange Perez, pelas revisão das traduções do Francês.

Aos meus colegas desembargadores do Tribunal Regional do Trabalho da $1^{\mathrm{a}}$ Região que votaram pela concessão de meu afastamento, concedendo-me assim a oportunidade única de poder dedicar-me ao estudo da Filosofia.

Aos meus pais. 


\section{Resumo}

Cunha, Sílvia Regina da Silva Barros da Cunha; Iglésias, Maura. As Marionetes Divinas: O Fundamento da Responsabilidade Moral no Pensamento de Platão. Rio de Janeiro, 2011. 91 p. Dissertação de Mestrado - Departamento de Filosofia, Pontifícia Universidade Católica do Rio de Janeiro.

Numa perspectiva objetiva, o fundamento da responsabilidade moral é objeto do Livro IX das Leis, onde Platão desenvolve sua teoria da punição, baseada na tese de que ninguém comete o mal voluntariamente, que ele concilia com a necessidade prática de graduar as penas, a partir da distinção tradicional entre delitos voluntários e involuntários. Identificando no delito dois aspectos independentes, dano e injustiça, Platão afirma que o primeiro requer apenas reparação, enquanto a punição é concebida como medida destinada a melhorar a alma afetada por emoções desordenadas ou por ignorância, causas da injustiça. $\mathrm{O}$ problema em foco apresenta também um aspecto subjetivo: independentemente das vantagens sociais da justiça, da ótica exclusiva do indivíduo em sua relação consigo próprio, haveria alguma razão que justificasse ser justo? Para Platão, a injustiça causa uma ruptura da harmonia da alma, rompendo o diálogo interno do eu consigo mesmo e afetando a capacidade de pensar. Nos diálogos tardios, à medida que evolui a concepção de Platão acerca das fontes do mal, resta claro que a punição pelas injustiças não depende da sobrevivência da alma após a morte, pois decorre da lei universal de atração dos semelhantes, por força da qual a maldade leva o injusto a conviver com o mal, devastando sua vida interior.

\section{Palavras-chave}

Leis; Responsabilidade moral; Fontes do mal em Platão; Punição. Injustiça. 


\section{Abstract}

Cunha, Sílvia Regina da Silva Barros da Cunha; Iglésias, Maura (Advisor). The Gods' Puppets: The Foundation of Moral Responsibility in Plato's Thought. Rio de Janeiro, 2011. 91 p. MSc. Dissertation Departamento de Filosofia, Pontifícia Universidade Católica do Rio de Janeiro.

From an objective point of view, Book IX of the Laws is concerned with the foundation of moral responsibility, a central issue in Plato's theory of punishment, which couples the socratic thesis that no one commits evil willingly, with the practical necessity for a gradation of penalties, which is derived from the traditional distinction between voluntary and involuntary crimes. Distinguishing two independent aspects of wrongdoing - damage and injustice - Plato argues that the former requires only atonement, whereas punishment is conceived as a measure to improve the soul, affected by disordered emotions or ignorance, causes of injustice. This question also presents a subjective aspect: from the agent's point of view, in his relation with himself and disregarding the social advantages of justice, is there any reason to be fair? For Plato, injustice tears the soul's harmony, preventing the internal dialogue of a person with himself and affecting his capacity to think. In his later dialogues, as Plato's conceptions about the sources of evil evolve, it remains clear that punishment for injustice does not depend on the soul's survival after death, but springs from a universal law according to which like clings to like, a principle which determines that evil induces the wicked to live with evil, disrupting his inner life.

\section{Keywords}

Laws; Moral responsibility; Plato's sources of evil; Punishment; Injustice. 


\section{Sumário}

1. Introdução

2. O problema da acrasia e a evolução da tese oudeis hekon hamartanei no pensamento de Platão

3. O fundamento da responsabilidade moral sob o enfoque objetivo - a teoria da punição exposta no livro XI das Leis

3.1. A enunciação do princípio maior acerca da ação e o problema por ele suscitado - 860c7-861a2

3.2. O reconhecimento da existência de duas classes de delitos e a retomada do paradoxo sobre a justiça - 861a3$861 d 9$

3.3. A distinção entre dano (blabe) e injustiça (adikia) 861e1-863a

3.4. As causas das faltas cometidas pelos homens e os múltiplos aspectos do voluntário e do involuntário - 863a3$864 \mathrm{c} 9$

3.5. Nova exposição da diferença entre injustiça e dano 863e5-864c8

4. O aspecto subjetivo do fundamento da responsabilidade moral - a doença da alma

5. Conclusão

6. Bibliografia 
$\tilde{\eta} \theta 0 \varsigma \dot{\alpha} v \theta \rho \omega ́ \pi \omega \delta \alpha \dot{\mu} \mu \omega \nu$

O caráter é o destino do homem.

Heráclito, Fragmento D. 119 